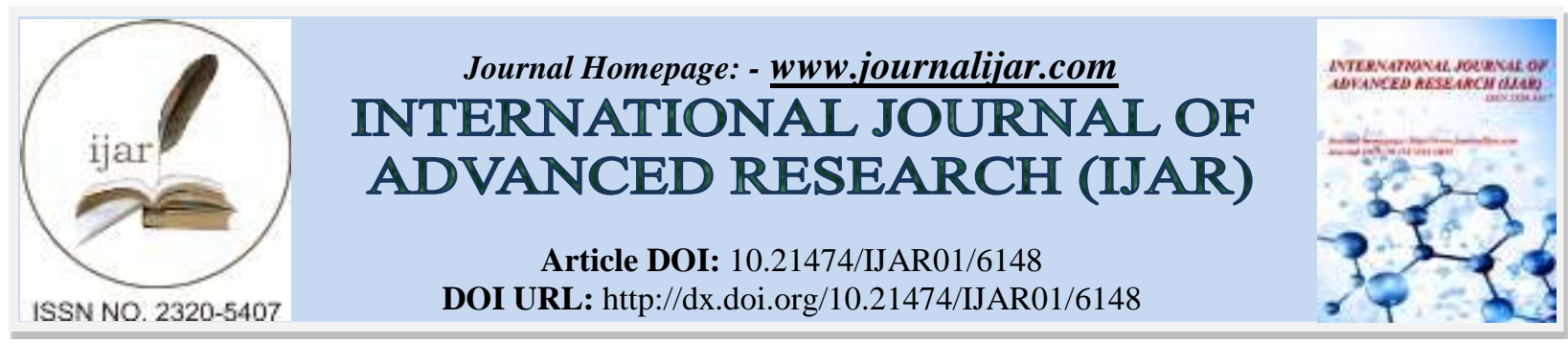

RESEARCH ARTICLE

\title{
GROWTH, X-RD AND THERMAL STUDIES OF FERROELECTRIC GLYCINE POTASSIUM SULPHATE (GPS) CRYSTALS.
}

\author{
I. J. Patil.
}

Dept. of Physics P.S.G.V.P.M' Arts Comm. Science College Shahada - 425409.

\section{Manuscript Info}

Manuscript History

Received: 23 October 2017

Final Accepted: 25 November 2017

Published: December 2017

Key words:-

$\mathrm{A}_{1}$ Growth from Solution, $\mathrm{A}_{2}$

Characterization, $\mathrm{B}_{1}$ Organic Compound,

$\mathrm{B}_{2}$ Ferroelectric GPS Crystal.

\section{Abstract}

Growth, X-RD and Thermal studies of Ferroelectric Glycine Potassium Sulphate (GPS) Crystals

\section{Introduction:-}

The factors, affecting on crystal growth ${ }^{[1]}$ are presence of impurities, changing temperature and the $\mathrm{PH}$ of the solution to grow good crystal of appreciable size for investigation of mechanical, Physical, electrical and other properties ${ }^{[2]}$. To grow the crystal in laboratory for water soluble components is by separation from aqueous solution. Though the crystallization ${ }^{3}$ from a solution is in general of on good quality than those obtained by other method, the uniformity of the growth, depends on the fact that the slower the growth the atoms, ions or molecule, have to pack together to form an ideal crystal. The ideal crystal is one which is space lattice continues from side to side. The excessive supper cooling is avoided by rapid stirring of cooling solution to insure that the crystal which form first at the evaporating surface are distributed throughout the solution ant the uniform growth in all directions will result ${ }^{[4,5]}$ .In recent years, oregano-inorganic hybrid materials ${ }^{[6]}$ have attracted considerable attention. In particular, the inorganic derivatives of protein amino acids are often attributed to symmetric groups ${ }^{[7]}$ without an inversion centre mostly to polar symmetry groups. Their crystals have properties whose symmetry is described by odd -rank tensors such as pyro-electric effect, spontaneous electric polarization, piezoelectric effect, generation of second optical harmonics, ${ }^{[8,9]}$ etc. Single crystals of Tri- Glycine Potassium Sulphate crystals (TGPS), a semi organic nonlinear optical material has been grown from solution by slow evaporation at ambient temperature ${ }^{[10,11]}$. The chemical composition of the grown crystals was determined by the FTIR spectra. The structure is built from alternate layers of Glycine organic molecules and inorganic layers consisting of $\mathrm{K}^{+}$ions and $\mathrm{So}_{4}{ }^{-}$ions. The grain size is found to be 5 microns

\section{Experimental:-}

Synthesis and crystal growth:-

A number of experimental techniques have been employed during the present of work. Application of various experimental technique ${ }^{[13]}$ employed depending on factors like basic principles involved advantages and limitation of each method. Among that the crystals with different proportion i.e. 1:1 and 3:1 were grown from aqueous solution by slow evaporation technique at room temperature. The $\mathrm{pH}$ of the solution at super-saturation is kept at 6.0. The 
solution is filtered and transferred to a Petri dish and biker for crystallization. This compound is re-crystallized two times for purity.

Crystals of good quality appeared after about two weeks \& crystals of appreciable size are obtain within six to eight weeks time fully grown crystal of GPS-I \& GPS-II are shown in Fig. 1 (a) \& 1 (b).

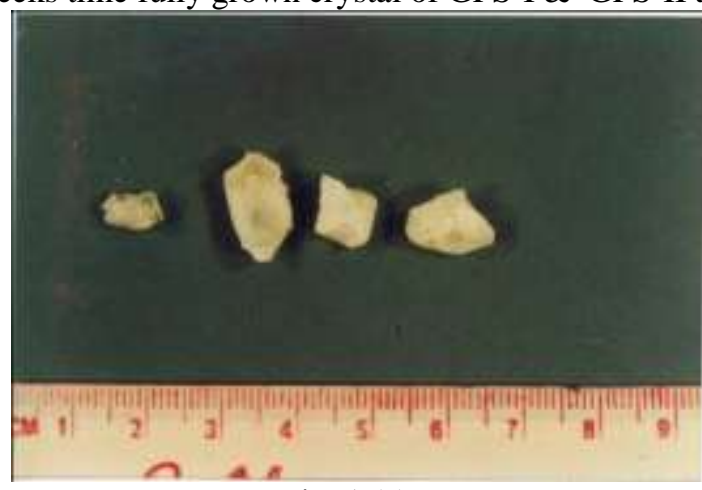

Fig. 1 (a)

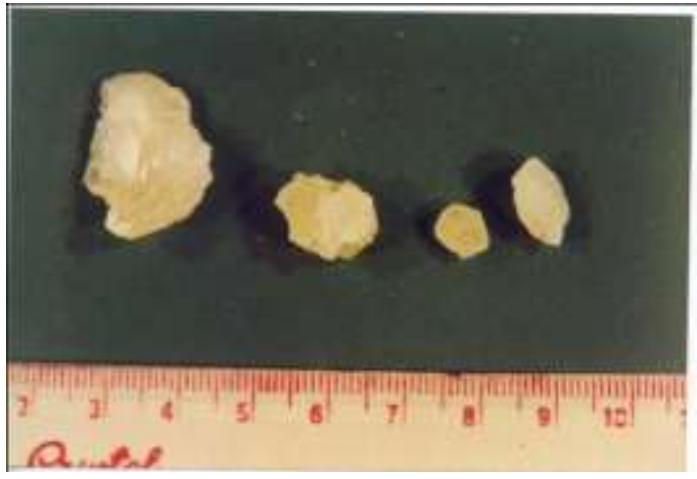

Fig. 1 (b)

This method is extensively used for purifying and obtaining single crystals of organic \& inorganic materials. The factor affecting on crystal growth are presence of impurities, changing temperature $\&$ the $\mathrm{pH}$ of solution to grow good crystals of appreciable size. Then the pure samples of seed crystals are taken and characterize as X-RD \& other properties.

\section{Characterization: (X-ray structure analysis):-}

To determine the crystal structure (cell constant) of GPS crystals, $\mathrm{x}$-ray diffraction (XRO) with $\mathrm{Cu}_{2} \square$ radiation $\left(\square_{\square}=\right.$ $1.540 \mathrm{Au}$ and $\left.\square_{\square}=1.544 \mathrm{Au}\right)^{\theta}$ at various angle range of $2^{\theta}\left(5^{0}<145^{\circ}\right)$ were recorded at rate of 2 deg. per min. The resulting X-ray profiler are shown Fig. 2 (a) \& 2 (b) for GPS-I, GPS-II crystals respectively.

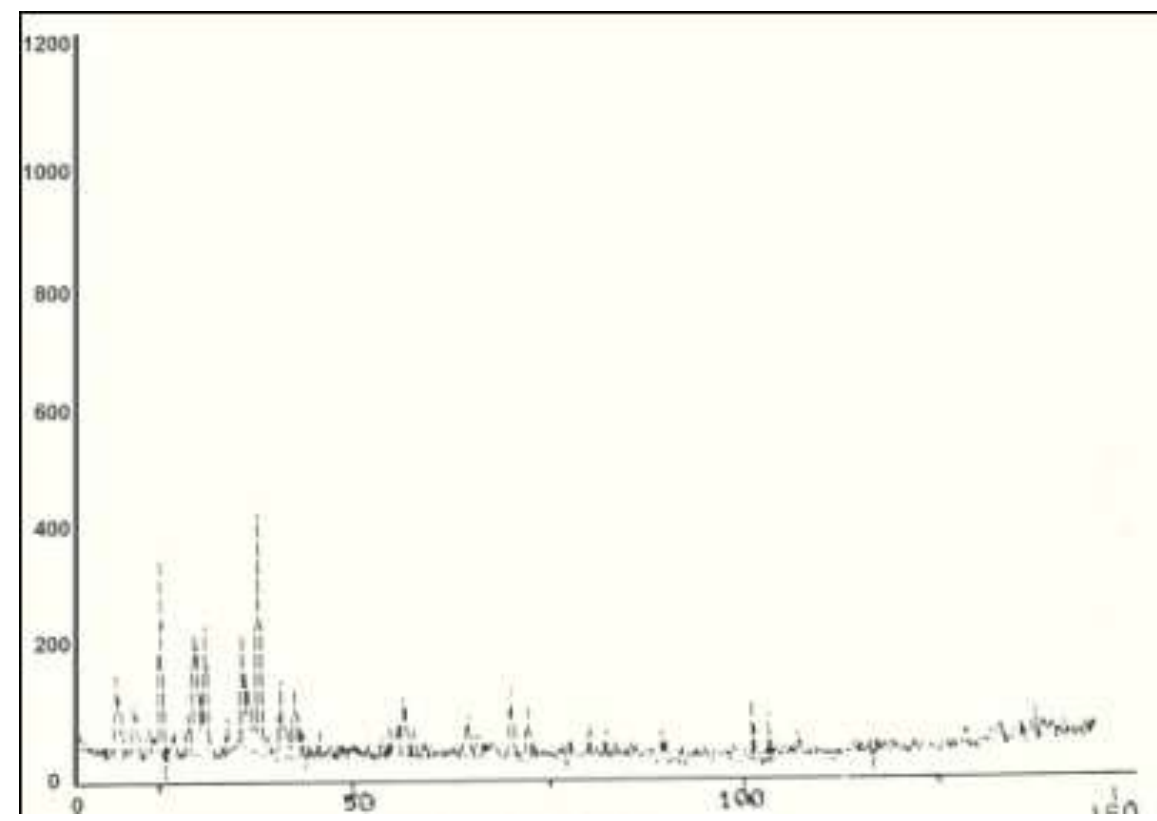

Fig. 2 (a) 


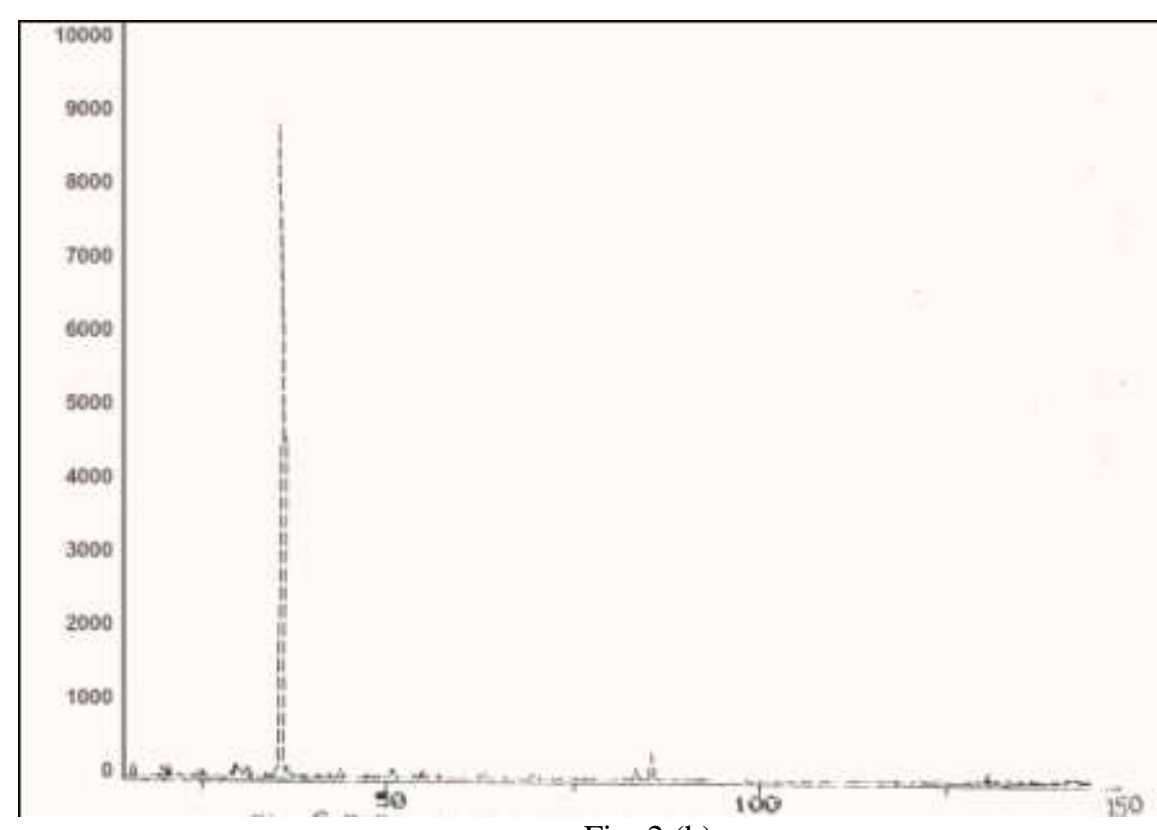

Fig. 2 (b)

The prominent peaks are in the range of $20^{\circ} \mathrm{C}$ to $80^{\circ} \mathrm{C}$ in both samples. The compassion of observed and calculated of value of some reflection of GPP-I and GPP-II at room temperature is given in table- I \& II from the analysis of $\mathrm{X}$-ray data \& using least squares method.

Table I:- XRD Data of GPS I

Observed and calculated d Value of some reflection of GPS_I at room temperature.

\begin{tabular}{|l|l|l|l|l|}
\hline 20 Deg. & h k l & d obe. & d.cal. & I/Imax. \\
\hline 25.58 & 120 & 3.481 & 3.480 & 100.00 \\
\hline 30.20 & 130 & 2.947 & 2.954 & 33.24 \\
\hline 31.22 & 121 & 2.862 & 2.780 & 37.47 \\
\hline 35.91 & 050 & 2.498 & 2.500 & 27.37 \\
\hline 38.05 & 002 & 2.363 & 2.357 & 28.50 \\
\hline 38.55 & 012 & 2.333 & 2.316 & 7.90 \\
\hline 40.44 & 022 & 2.218 & 2.206 & 13.70 \\
\hline 43.49 & $210 / 060$ & 2.079 & 2.065 & 8.72 \\
\hline 56.75 & 170 & 1.620 & 1.642 & 18.54 \\
\hline 70.02 & 301 & 1.342 & 1.340 & 21.40 \\
\hline 82.21 & 004 & 1.171 & 1.178 & 10.26 \\
\hline 132.39 & 235 & 0.841 & 0.841 & 11.67 \\
\hline
\end{tabular}

Table II:- XRD Data of GSP II

Observed and calculated d Value of some reflection of GPS-II at room temperature.

\begin{tabular}{|l|l|l|l|l|}
\hline 20 Deg. & h k l & d obe. & d.cal. & I/Imax. \\
\hline 19.05 & 001 & 4.655 & 4.605 & 3.70 \\
\hline 25.20 & 120 & 3.531 & 3.535 & 14.18 \\
\hline 29.25 & 111 & 3.050 & 3.047 & 5.90 \\
\hline 30.10 & 130 & 2.966 & 2.958 & 6.17 \\
\hline 30.60 & $140 / 031$ & 2.519 & 2.519 & 100.00 \\
\hline 36.06 & 050 & 2.488 & 2.486 & 70.40 \\
\hline 36.70 & 101 & 2.446 & 2.443 & 14.59 \\
\hline 50.75 & 070 & 1.797 & 1.776 & 35.22 \\
\hline 55.21 & 231 & 1.662 & 1.662 & 3.24 \\
\hline 69.65 & 330 & 1.348 & 1.350 & 32.52 \\
\hline 83.03 & 004 & 1.158 & 1.163 & 3.29 \\
\hline
\end{tabular}


Table III:- Cell Parameter of GPS Crystal

\begin{tabular}{|l|l|l|l|l|l|}
\hline Ob No & Sample Name & A Au. & B Au. & C.Au. & Volume \\
\hline 1 & GPS -I & 4.035 & 12.659 & 4.677 & 238.36 \\
\hline 2 & GPS-II & 4.303 & 12.403 & 4.605 & 245.80 \\
\hline 3 & G1k & 3.531 & 6.124 & 5.479 & 118.47 \\
\hline 4 & G3K & 3.545 & 6.143 & 5.506 & 119.90 \\
\hline
\end{tabular}

Thermal Properties (TGA / DTG \& DSC):-

(i) Thermogravimetry and Derivative thermogravimetry (TGA / DTG) :

Thermogravimetry is the technique in which the mass $(\mathrm{m})$ or change in mass $(\mathrm{m})$ of substance heated or cooled at a controlled rate, is recorded as a function of time and temperature. The record is referred to as a thermogravimetry (TGA or DTG).

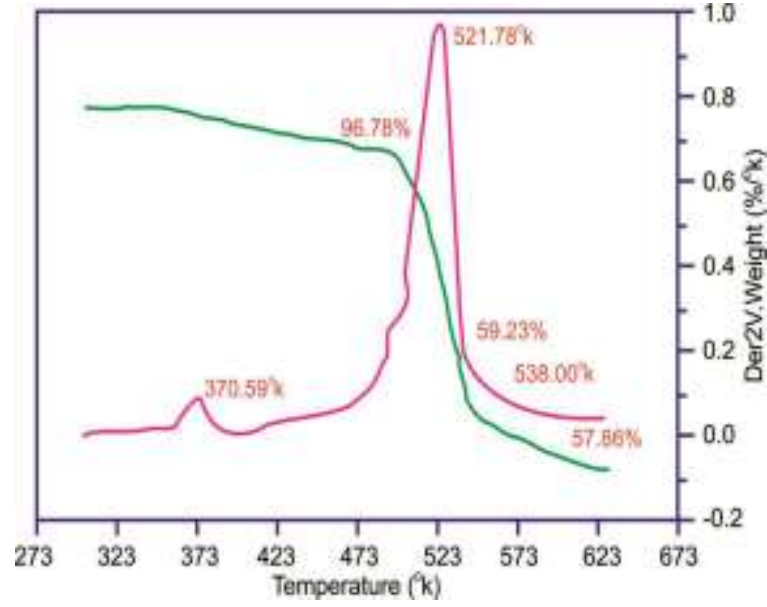

Fig3: TGA DTG of GPS-I

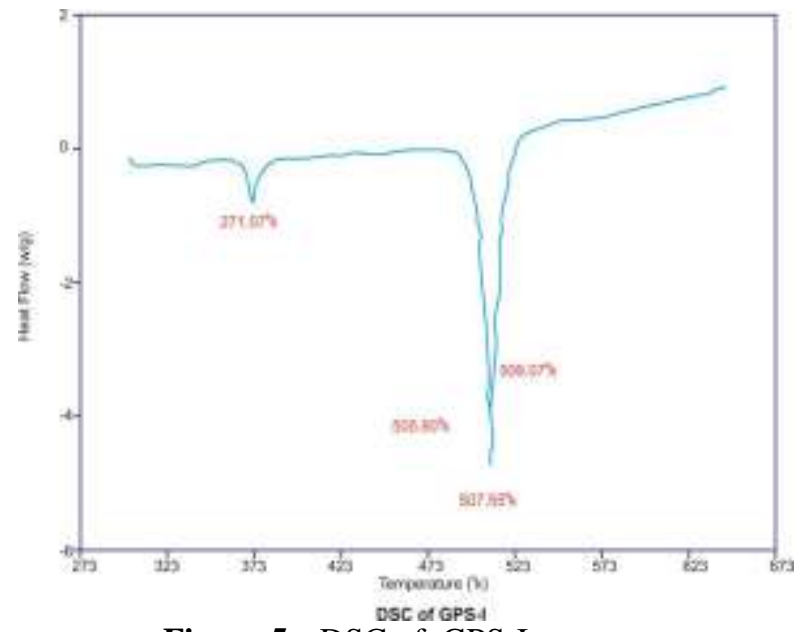

Figure 5:- DSC of GPS-I

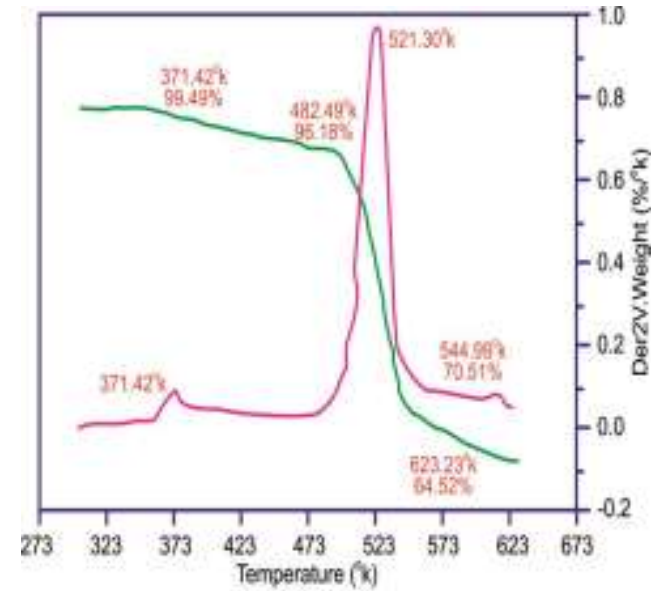

Fig.4 TGA DTG of GPS-II

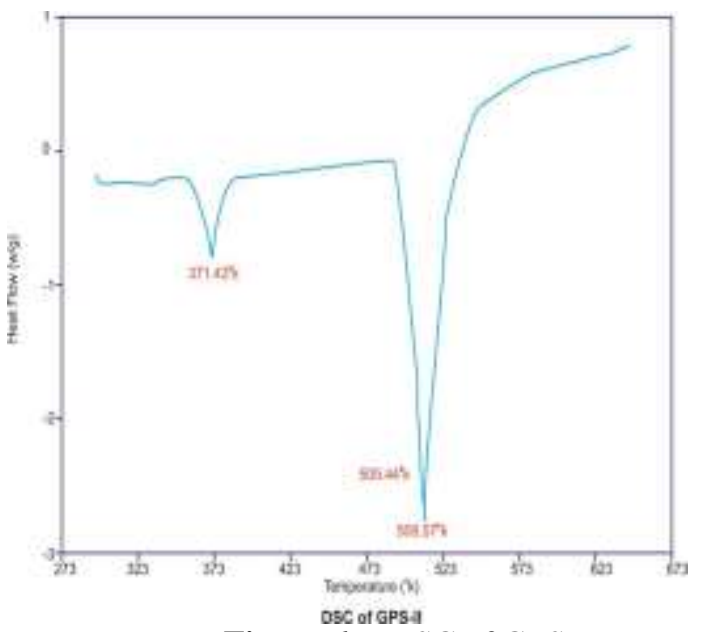

Figure 6:- DSC of GPS-II

Crystal in powdered form was subjected to thermal analysis between temperature range. From room temperature to $673^{\circ} \mathrm{k}$ in inert nitrogen atmosphere at the rate of $278^{\circ} \mathrm{k} / \mathrm{min}$ and $283^{\circ} \mathrm{k} / \mathrm{min}$ platinum sample holder was used for TGA and copper for DSC measurement. A typical TGA curve represent a plot of \% weight against temperature, the DTG curves on the same graph shows derivative thermogravimetry as derivative weight versus temperature. Fig-3 \& Fig.-4 shown thermo gravimetric (TGA / DTG) curve for GPS-I \& GPS-II respectively, and fig.-5 and fig-6 shows DSC curve for GPS-I \& GPS-II respectively It is observed that within the prescribed temperature range they represent decomposition of the sample in single stage Table-IV show corresponding decomposition temperature for GPS-I \& GPS-II crystal obtained by TG / DTG and DSC curves. 
Table IV:- Decomposition temperature from TGA/DTG and DSC

\begin{tabular}{|l|l|l|l|l|l|}
\hline Ob No & Compound & $\begin{array}{l}\text { Decomposition } \\
{ }^{\circ} \mathrm{k} \text { TGA }\end{array}$ & Rate ${ }^{\circ} \mathrm{k} / \mathrm{min}$ & $\begin{array}{l}\text { Temperature } \\
{ }^{\circ} \mathrm{k} \text { DSC }\end{array}$ & Rate ${ }^{\mathrm{o}} \mathrm{k} / \mathrm{min}$ \\
\hline 1 & GPS -I & 538 & 278 & 513.48 & 283 \\
\hline 2 & GPS-II & 544.99 & 278 & 513.48 & 283 \\
\hline 3 & GKF & 538 & 278 & 523 & 283 \\
\hline
\end{tabular}

\section{Result and Discussion:-}

\section{Geometry of grown crystals}

The shape of number of crystals of various sizes has been studied.

Crystal w i th $18 \times 15 \times 3 \mathrm{~mm}^{3}$ sizes shows the geometry as represented in figure 7 and 8

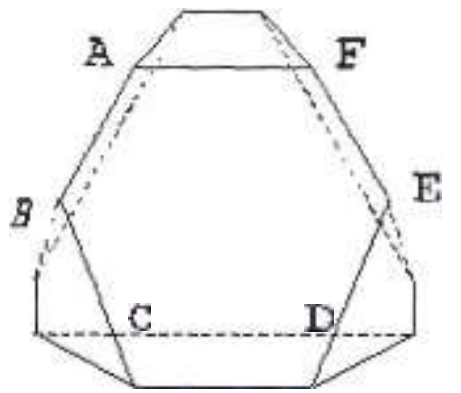

Fig. 7:- Development With triangular Structure.

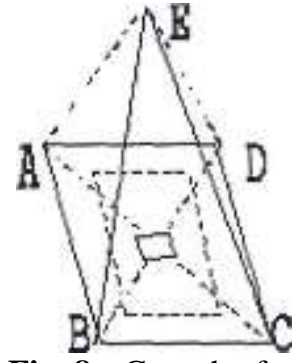

Fig. 8:- Growth of periodical crystal

However, the crystal geometry is nearly identical to the one reported by Sawada et a 1 [9]. The schematic diagrams have drawn using the dimensions of the grown crystals. Triangular faces with truncated corners in fig. 1 represents [111] family plane, where as the bottom face of crystals such as in fig. 8 corresponds to [110] family as is evident from the crystalsymmetry.

During the growth of crystal, it is noted that the $\mathrm{PH}$ of the solution is more important than the molar ratio. With addition of $\mathrm{K}_{2} \mathrm{So}_{4}$ to glycine the external growth features are drastically altered. Whitish crystals are suitable for dislocation studies, Change in proportion does not affect the external geometry of the crystal while the physical nature of crystal is same, as that of glycine when heated i.e. decomposition to brown colour.

From X-RD studies, cell parameters for various planes are calculated. A good agreement between calculated and observed of values suggests that the compound is orthorhombic with lattice. Parameter is given in table-III along with the cell volume. It is observed that the cell volume of GPS-II is greater than that of GPS-I crystal on (120) and (140/060) plane exhibiting the maximum characteristic intensity for GPS-I and GPS-II respectively. There is initially decrease \& then increase again.

From Thermal studies, the decomposition temperature of both GPS-I \& GPS-II crystal is found $513^{0} \mathrm{k}$. The DTG peaks at about $0.98 \% / \mathrm{k}$. The decomposing rate loss is less which can be understood that potassium sulphate is ionic. The strength of bond between glycine \& potassium sulphate is more. Bond energy is more therefore rate of decomposition is less.

DSC studies revels no ferroelectric transition in temperature range from room temperature to $573^{0} \mathrm{k}$. All the reaction is exothermic exhibition sharp isotherms around $513^{0} \mathrm{k}$. The heat flow is seen to increase from GPS-I (1:1) to GPSII (3:1). 


\section{References:-}

1. S.K. Kurtz and T.T. Perry, J. Appl. Phys., 39, 3798 (1968)

2. R.K. Khanna and P.J. Miller, Spectro Chem. Acta, 26A, 1667, (1970).

3. Deshmukh, K.G. and Ingale, S.G., Curr. Sci. 1970, 16, 368.).

4. N.N. Bhat and S.M. Dharmaprakash, J. Cryst. Growth, 236, 376, (2002).

5. B.N. Moolya, A. Jayarama, M.R. Sureshkumar and S.M.D. harmaprakash, J. Cryst. Growth, 280, 581, (2005).

6. Bhide, V.G. and Bapat, N.J., J.Appl. Phys., 1963, 34, 181.

7. R. Silverstein, G.C. Bassler and T.C. Morrill, Spectrometric Identification of Organic Compounds, John Wiley \& Sons, (1991

8. Towler, C.S., Davey, R.J., Lancaster, R.W., Price C.J, J. Am. Chem. Soc., 2004, 126,

9. Toyada, H., Waku, S. and Hirabriyashi, H., IBID, 1959, 14, 1003.

10. Toyada, H. J., Phys. Soc. Japan, 1960, 15, 1539.

11. Ingale, S.G., Chaudhari, R.M. and Mishra, M.B., Ind. J. Pure Appl. Phys., 1978, 15, 323.

12. Kulkarni, R.H., Chaudhari, R.M. and Ingale, S.G., J.Phys. D. Appl. Phys. 1974, 6, 181613334.

13. Dawson, A., Allan, D.R., Belmonte, S.A., Clark, S.J., David, W.I.F., McGregor, P.A., Parson, S., Pulham, C.R., Sawyer, L., Cryst. Growth Des., 2005, 5, 1415 